\title{
Relato de experiência da vacinação da Tríplice Viral (Sarampo, Caxumba, Rubéola) nas escolas estaduais de Manaus-AM, contra o surto de Sarampo em 2018
}

\author{
Experience report of the Viral Triple vaccination (Measles, Mumps, Rubella) in Manaus- \\ AM state schools, against the measles outbreak in 2018 \\ Relato de experiencia en la vacunación del Triple Viral (Sarampo, Setas, Rubella) en las \\ escuelas estatales de Manaus-AM, contra el brote de medición en 2018 \\ Josy Lira Dias ${ }^{1 *}$, Maria Izabel Nogueira do Nascimento.
}

\section{RESUMO}

Objetivo: Descrever a experiência durante a realização da vacinação da Tríplice Viral (Sarampo, Caxumba e Rubéola) nas escolas estaduais de Manaus-AM, contra o surto de Sarampo em 2018. Relato de experiência: Este relato narra a experiência vivenciada em ação de intensificação vacinal promovido em parceria com a Fundação de Vigilância em Saúde através do Programa Estadual de Imunização e a Secretaria de Educação do Amazonas. Foi observado que tiveram muitas aplicações de primeira dose, apresentando recusas em todas as zonas e identificando dificuldades em algumas escolas em atendimento aos critérios necessários a vacinação e a pouca adesão dos administrativos e professores a vacinação. Considerações finais: É necessário continuar a sensibilizar os pais, gestores, professores, funcionários e os alunos quanto a importância de a vacinação estar completa de acordo com o calendário vacinal. Devido ao número de primeiras doses fica a preocupação do fechamento do esquema evitando assim bolsões de susceptíveis. Os profissionais da educação estão expostos a riscos principalmente a doenças contagiosas, a vacinação se faz necessária para este público, porém a vacinação dos funcionários e professores das escolas estaduais de Manaus ainda não teve adesão em grande escala quanto a vacina Tríplice Viral.

Palavras-chave: Vacina contra Sarampo-Caxumba-Rubéola, Vacinação, Sarampo.

\begin{abstract}
Objective: Describe the experience during the vaccination of the Triple Viral (Measles, Mumps and Rubella) in the state schools of Manaus-AM, against the measles outbreak in 2018. Experience report: This report narrates the experience lived in vaccination intensification action promoted in partnership with the Health Surveillance Foundation through the State Immunization Program and the Amazonas Department of Education. It was observed that they had many applications of first dose, presenting refusals in all areas and identifying difficulties in some schools in meeting the necessary criteria for vaccination and the low adherence of administrators and teachers to vaccination. Final considerations: It is necessary to continue to raise awareness among parents, managers, teachers, staff and students about the importance of complete vaccination according to the vaccination schedule. Due to the number of first doses, there is the concern of closing the scheme thus avoiding pockets of susceptible. Education professionals are exposed to risks mainly to contagious diseases, vaccination is necessary for this public, however the vaccination of employees and teachers of Manaus state schools has not yet had large-scale adherence to the Triple Viral vaccine.
\end{abstract}

Keywords: Measles-Mumps-Rubella vaccine, Vaccination, Measles.

\footnotetext{
${ }^{1}$ Programa Estadual de Imunização do Amazonas, Manaus - AM.
}

*E-mail: joliradias@hotmail.com

SUBMETIDO EM: $8 / 2020$

ACEITO EM: 9/2020

PUBLICADO EM: 11/2020

REAS/EJCH |Vol.12(11) | e4909 | DOI: https://doi.org/10.25248/reas.e4909.2020 Página 1 de 6 


\section{RESUMEN}

Objetivo: Describa la experiencia durante la vacunación del Triple Viral (Sarampión, Paperas y Rubéola) en las escuelas estatales de Manaus-AM, contra el brote de sarampión en 2018. Informe de experiencia: Este informe narra la experiencia vivida en la acción de intensificación de la vacuna promovida en asociación con la Fundación de Vigilancia de la Salud a través del Programa de Inmunización del Estado y el Departamento de Educación de Amazonas. Se observó que tenían muchas aplicaciones de primera dosis, presentando rechazos en todas las áreas e identificando dificultades en algunas escuelas para cumplir con los criterios necesarios para la vacunación y la baja adherencia de los administradores y maestros a la vacunación. Consideraciones finales: Es necesario continuar creando conciencia entre padres, gerentes, maestros, personal y estudiantes sobre la importancia de completar la vacunación de acuerdo con el calendario de vacunación. Debido al número de primeras dosis, existe la preocupación de cerrar el esquema evitando así focos de susceptibles. Los profesionales de la educación están expuestos a riesgos principalmente a enfermedades contagiosas, la vacunación es necesaria para este público, sin embargo, la vacunación de los empleados y maestros de las escuelas estatales de Manaus aún no ha tenido una adhesión a gran escala a la vacuna Triple Viral.

Palabras clave: Vacuna contra el Sarampión, Vacunación, Sarampión.

\section{INTRODUÇÃO}

O Programa Nacional de Imunização (PNI) criado em 18 de setembro de 1973, e com o passar dos anos possibilitou a inclusão social das vacinas para toda à população brasileira, através de ações de qualidade em todas as faixas etárias da vida, trabalhando a vacinação de rotina, a intensificação vacinal, as campanhas de vacinação anuais e ações extra muro (BRASIL, 2003). Existe um empenho mundial para o fortalecimento dos programas de vacinação, principalmente nos países em desenvolvimento, buscando aumentar a cobertura vacinal e implantar novas vacinas nos programas de vacinação (HOMMA A, et al., 2011).

As vacinas possibilitam a prevenção, a contenção, a eliminação e a erradicação das doenças imunopreveníveis, trabalhando com a diminuição da morbimortalidade por algumas doenças e tendo um grande aproveitamento de custo e efetividade (BRASIL, 2014a).

O Sarampo é uma doença infecciosa exantemática aguda, transmissível e muito contagiosa, pode evoluir com complicações e óbito, principalmente em crianças com desnutrição e menores de um ano de idade. A transmissão ocorre de pessoa a pessoa, por meio de secreções respiratórias, no período de quatro a seis dias antes do aparecimento do exantema até quatro dias após (BRASIL, 2018a).

O Ministério da Saúde preconiza que o calendário de vacinação contra o sarampo deve ser: uma dose da vacina Tríplice Viral (Sarampo, Caxumba, Rubéola) aos 12 meses de idade; uma dose da Tetraviral (Sarampo, Caxumba, Rubéola, Varicela) aos 15 meses de idade, de acordo com a Superintendência de Vigilância em Saúde na nota técnica no. 26/2018; duas doses da vacina tríplice viral entre dois e 29 anos de idade; e uma dose da vacina tríplice viral dos 30 aos 49 anos de idade, de acordo com a situação vacinal encontrada (BRASIL, 2002; SUVISA, 2018).

Desde 2001, os raros casos de sarampo registrados no Brasil foram importados, antes de ser controlada, era uma das maiores causas de mortalidade infantil, por isso foi implantado em 1992 o Plano Nacional de Controle e Eliminação do Sarampo e à vigilância epidemiológica da doença no país (BRASIL, 2018b).Em 2015, foram registrados 211 casos de sarampo no Estado do Ceará, 02 em São Paulo e 01 em Roraima, relacionado ao surto do Ceará, após várias ações de vigilância, análises laboratoriais e imunizações, no ano de 2016, o Brasil recebeu o certificado de eliminação da circulação do vírus do sarampo pela OMS, declarando a região das Américas livre do sarampo.

A Venezuela enfrentou um surto de sarampo, desde julho de 2017, devido a sua situação sociopolítica e econômica, acarretou um grande movimento migratório, contribuindo para a propagação do vírus, incluindo o Brasil que enfrentou surtos de sarampo nos estados de Roraima e do Amazonas (BRASIL, 2018a), desse modo perdendo a certificação. A Fundação de Vigilância em Saúde/AM, em parceria com as autoridades de Saúde do Estado e dos municípios com casos notificados, trabalho na intensificação das ações de vigilância 
epidemiológica, imunização e laboratorial para interromper a transmissão do vírus, buscando conter o surto no Amazonas, a capital Manaus apresenta $78,6 \%$ de casos notificados (FUNDAÇÃO DE VIGILÂNCIA SAÚDE, 2019).

Da Semana Epidemiológica 6/2018 a 2/2019, foram notificados 11.355 casos suspeitos de sarampo provenientes de 50 municípios no estado do Amazonas, foram confirmados 86,2\% (9.789), descartados $13,8 \%$ (1.563) e estão sob investigação $0,03 \%$ (3). Com predomínio no sexo masculino $(55,6 \%)$ e em crianças menores de 5 anos (28,3\%), seguido da faixa etária de 20 a 29 anos $(25,0 \%)$ e de 15 a 19 anos $(21,2 \%)$ (HOMMA A, et al., 2011). Neste sentido o estudo tem como objetivo socializar a experiência durante a realização da vacinação da Tríplice Viral (Sarampo, Caxumba e Rubéola) nas escolas estaduais de ManausAM, contra o surto de Sarampo em 2018.

\section{RELATO DE EXPERIÊNCIA}

Esta experiência foi desenvolvida por meio da ação de intensificação vacinal desenvolvida no ano de 2018 entre os meses de agosto a dezembro, que contou com o apoio da Fundação de Vigilância em Saúde através do Programa Estadual de Imunização em parceria com a Secretaria de Educação do estado do Amazonas.

Para que fosse possível trabalhar a vacinação nas escolas, traçamos um planejamento das atividades junto com os assessores educacionais por zona da cidade de Manaus no estado do Amazonas, onde eram repassados o quantitativo das escolas estaduais, a quantidade de alunos por escola, funcionários, professores e localização. Dessa maneira fizemos uma avaliação do quantitativo de enfermeiros, vacinadores e voluntários do curso de enfermagem de uma instituição particular específico para cada escola, assim como a quantidade de doses e seringas a serem utilizadas.

Foi realizado o agendamento com a gestão da escola previamente a data da vacinação através dos gestores da Secretaria de Educação por zona, onde foi pedido que cada escola enviasse para os pais ou responsáveis a autorização que deveria ser assinada, com o nome completo do aluno e série. Cada aluno deveria levar a autorização assinada e o cartão de vacina para avaliação da vacina tríplice viral (Sarampo, Cachumba e Rubéola).

Em cada escola agendada, nos identificávamos aos gestores, que providenciavam uma sala climatizada para que pudéssemos organizar o fluxo de avaliação, educação em saúde e a aplicação das doses. Em meio ao surto de casos de sarampo na cidade de Manaus, a preocupação era em realizar a vacinação de forma correta e em tempo para que diminuísse a possibilidade desses alunos contraírem a doença. Depois de uma avaliação da caderneta de vacina e a checagem das autorizações assinadas, os alunos que necessitavam de doses da vacina tríplice viral (SCR) eram encaminhados para a sala de vacinação. A escola fornecia a lista dos alunos por sala e turno, ao lado era colocado a data de nascimento e o nome da mãe, alguns se negavam a dar o nome da mãe por situações pessoais.

Era preenchido o cartão ou o comprovante de vacina e encaminhado para a vacinação in loco, no caso dos professores e funcionários foi disponibilizado uma folha para ser colocado nome completo, nome da mãe, data de nascimento e a dose, após a aplicação da vacina recebiam o comprovante da vacinação ao cartão de vacina preenchido.

Como foi trabalhado por zona, onde no município de Manaus, são divididos em cinco, sendo elas Norte, Sul, Centro-Sul, Leste e Oeste, o total de alunos das escolas estaduais informado pela SEDUC não foi igual ao quantitativo encontrado devido a duplicidade do nome do aluno normalmente devido a troca de turno. Ao finalizar cada turno era recolhido todo o material, agradecíamos o acolhimento da escola e caso ainda não tivéssemos finalizado a avaliação em todos os alunos por sala de aula, era reagendado até a finalização de todas as ações.

\section{DISCUSSÃO}

Devido a variação de estrutura das escolas e da própria gestão local, em alguns momentos encontramos dificuldade em atender os requisitos básicos para que pudéssemos fazer a educação em saúde e as vacinas de maneira mais eficaz e algumas vezes passávamos vários dias em uma escola para conseguir fazer todo o procedimento proposto. 
A educação em saúde é apontada como parte importante da prevenção, faz com que a pessoa comece a questionar a sua saúde e uma ideia de possível mudanças. O Ministério da Saúde indica que a escola é um local de relevância para a concepção de conhecimento a respeito da de saúde e a busca de uma vida mais saudável (BRASIL, 2003). As atividades educativas desenvolvidas consistiram em uma conversa sobre a vacina tríplice viral, seus benefícios e as contraindicações. Abríamos para questionamentos e tirávamos as dúvidas dos alunos, trabalhamos a valorização individual e para a sociedade sobre a importância da vacinação contra o sarampo.

Para a consolidação destes costumes educativos é interessante que as equipes com experiências em educação em saúde, onde o enfermeiro mantém essa dinâmica entre a educação e a saúde de maneira a causar uma mudança real de atitudes e pensamentos. Se faz necessário buscar meios de interagir com as diferentes faixas etárias, na busca de conseguir sanar as dúvidas e medos existentes quanto a vacinação, suas contraindicações e mitos (BRASIL, 2005).

Torna-se essencial manter a educação em saúde em todas as práticas envolvendo ações de vacinação nas escolas, é um local muito propício a propagação de doenças virais como o sarampo devido ao aglomerado de alunos em ambiente fechado, em Manaus as salas são climatizadas devido ao clima quente e úmido.

Em países de clima tropical, a transmissão do sarampo pode aumentar depois da estação chuvosa, da humidade, da imunidade e a suscetibilidade da população devido à baixa cobertura vacinal abaixo de $95 \%$, e da circulação do vírus na área. Ocorre de forma endêmica e ocorrendo epidemias, podendo ser agravadas pela rotatividade da população em locais de aglomeração públicos como as escolas (BRASIL, 2009).

Alguns alunos não levaram a autorização assinada ou faltaram no dia agendado para as ações de vacinação, dificultando assim, saber se estavam com as doses corretas da vacina tríplice viral (SCR). Fazendo com que esse quantitativo de alunos não fosse avaliado. Demonstrando que é necessário realizar outras estratégias que possam ter um acompanhamento constante para este grupo de alunos afim de evitar os bolsões de susceptíveis. Um programa que pode auxiliar na atuação dentro da área escolar é o Programa Saúde na Escola (PSE), que teve seu início em 2007 pelo decreto 6286, de 5 de dezembro, e que atua para a formação integral dos estudantes da rede pública de educação básica por meio de ações preventivas, que promovam atenção à saúde (BRASIL, 2015).

Mesmo existindo a Portaria ํㅜ 597, de 08 de abril de 2004 que instituiu, em todo território nacional, os calendários de vacinação e que se faz um ponto obrigatório avaliação do cartão vacinal no ato da matrícula em creches, pré-escola, ensino fundamental, ensino médio e universidade o comprovante de vacinação deverá ser obrigatório, atualizado de acordo com o calendário e faixa etária estabelecidos nos Anexos I, II e III desta Portaria. Evidenciamos no período que ainda há necessidade de muitos ajustes no que tange a parceria entre a saúde e a educação no estado do Amazonas para que possam ser incentivadores de melhorias das ações e atenção de forma integral para todos os alunos e assim diminuindo a chance de propagação de surtos nestes ambientes.

Ao avaliar o quantitativo de vacinados, foi observado que $75 \%$ receberam a primeira dose (D1), o que preocupa, pois somente com a primeira dose, os mesmos não estão imunizados. Já que o esquema vacinal seria de duas doses para a vacina tríplice viral (SCR), essa falta do fechamento das doses gera acúmulo de susceptíveis, onde a transmissão do epidêmica do sarampo poderia continuar a ocorrer.

Mesmo a vacina contra o sarampo sendo eficiente e segura, devido a grupos anti-vacinas com falsas notícias nas redes sociais influenciam as pessoas e que não se vacinam e não deixam os filhos serem vacinados, surgindo bolsões de susceptíveis, facilitando a propagação da doença (MEDEIROS EA, 2020). E devido a faixa etária entre 1 a 19 anos ter um aumento no quantitativo de casos de sarampo confirmados no Amazonas no período, com 4.036 casos confirmados de um total de 9.789 . Foi verificado que entre a em crianças menores de 5 anos (28,3\%) e de 15 a 19 anos (21,2\%) (BRASIL, 2002).

Tiveram professores e funcionários administrativos que ainda precisavam realizar a vacinação com a dose única, e mesmo que pouca aceitação em algumas escolas, podemos avaliar como um ponto positivo em realizar tanto a educação em saúde sobre a vacina como a adequação do cartão vacinal.

REAS/EJCH |Vol.12(11) | e4909 | DOI: https://doi.org/10.25248/reas.e4909.2020 Página 4 de 6 
Levando este grupo a entender melhor sobre a vacina, a sua necessidade e caracterizando a fragilidade das pessoas que não estão com o cartão de vacina completo. É importante que nas escolas os professores e funcionários possam conhecer sobre a necessidade da vacinação estar atualizada e com isso, sensibilizando pais e alunos. Incentivando valorização das campanhas e intensificações vacinais nas escolas e beneficiando a sociedade como um todo (MOURA ADA, et al., 2018).

Houve recusas em todas as zonas da cidade de Manaus, isso dificultou a comprovação real pois a grande maioria dos alunos só avisava que não tinha a autorização, os pais não autorizavam por já estarem vacinadas, porém não mostravam comprovação em cartão. O desconhecimento sobre a importância da vacinação principalmente em momento de epidemia atrelado a um local de propagação propício.

Para minimizar a recusa vacinal, é fundamental que aos pais ou responsáveis tenham acesso à informação de maneira segura e confiável com os profissionais de saúde, utilizando as oportunidades para falar sobre as vacinas, tirando as dúvidas e demonstrando a sua eficácia em salvar milhões de vidas (SUCCI RCM, 2018).

As escolas que não tiveram vacinação foram aquelas que no momento do agendamento não conseguiram enviar as autorizações para os pais em tempo hábil, estavam em eventos escolares ou finalização do ano letivo. Dessa forma, dificultando a realização da ação e consequentemente mantendo o risco de contágio dos alunos, professores e funcionários no ambiente escolar como para a comunidade ao qual estavam inseridos.

Mesmo com tantos desafios enfrentados, a vacinação nas escolas estaduais no município de Manaus teve um grande apoio por parte dos pais, educadores, gestores e alunos, pois conseguimos alcançar nosso objetivo, onde no fim do ano letivo finalizamos todas as zonas do município.

A população escolar deve ser trabalhada de modo a unir a educação em saúde permanente, para que durante a vida, as pessoas possam aprender a entender e em sociedade, buscando não somente o seu bem estar mais também o da coletividade, gerando novos pontos de vista e atitudes quanto ao ser social e a saúde como um todo. Levando a repensar em novas maneiras de se trabalhar a saúde embasado no conceito da vigilância em saúde, trazendo a saúde para mais perto da população e com isso modificando a realidade (VIEGAS SMF, et al., 2019).

Ao ser trabalhada a intensificação vacinal ou campanhas de vacinação contra o sarampo oportuniza a captação dos indivíduos não vacinados contribuindo para a diminuição do risco desses indivíduos contraírem a doença e reduzindo ou até mesmo eliminando os bolsões de não vacinados (BRASIL, 2014b).

Diante dessa vivencia podemos identificar a necessidade de continuar a sensibilizar os pais, gestores, professores, funcionários e os alunos quanto a importância da vacinação estar completa de acordo com o calendário vacinal, pois muitos não tinham o cartão para a devida avaliação e torna-se imperativo identificar a necessidade de avaliar a situação vacinal desse público e de promover a sua atualização.

Devido à grande quantidade de primeira dose aplicada, fica a preocupação em alcançar a segunda dose para completar o esquema, levando ainda a ter bolsões de susceptíveis no município, com isso é imprescindível mais ações para garantir a segunda dose. Os profissionais da educação estão expostos a diversos riscos principalmente a doenças contagiosas, a vacinação se faz necessária para este público, porém a vacinação dos funcionários e professores das escolas estaduais de Manaus ainda não teve adesão em grande escala quanto a vacina tríplice viral.

\section{AGRADECIMENTOS}

Agradecemos a Fundação de Vigilância em Saúde do Amazonas (FVS-AM) por meio do Programa Estadual de Imunização do Amazonas pelo apoio com os vacinadores, as vacinas, transporte e toda logística necessária para a realização da vacinação. A Secretaria de Educação do Estado do Amazonas (SEDUC-AM) com os agendamentos nas escolas através dos gestores e disponibilização de espaço e atendimento das necessidades para se realizar a vacinação, ao Instituto de Ensino Superior Materdei por disponibilizar os voluntários do curso de graduação em enfermagem para a intensificação vacinal contra o sarampo. 


\section{REFERÊNCIAS}

1. BRASIL. Ministério da Saúde. Projeto Promoção da Saúde. Secretaria de Políticas de Saúde/MS. A promoção da saúde no contexto escolar. Ver Saúde Pública 2002; 36 (2):533-5.

2. BRASIL. Ministério da Saúde. Programa Nacional de Imunizações - 30 anos. Série C. Projetos e Programas e Relatórios. Brasília, 2003; 212p.

3. BRASIL. Ministério da Saúde. Secretaria de Gestão do Trabalho e da Educação na Saúde. Departamento de Gestão da Educação na Saúde. A educação que produz saúde / Ministério da Saúde. Secretaria de Gestão do Trabalho e da Educação na Saúde. Departamento de Gestão da Educação na Saúde. Brasília: Ministério da Saúde, 2005. 16p.

4. BRASIL. Ministério da Saúde. Secretaria de Vigilância em Saúde. Departamento de Vigilância Epidemiológica. Guia de vigilância epidemiológica/Ministério da Saúde, Secretaria de Vigilância em Saúde, Departamento de Vigilância Epidemiológica. 7. ed. Brasília: Ministério da Saúde, 2009; 816p.

5. BRASIL. Ministério da Saúde. Secretaria de Vigilância em Saúde. Departamento de Vigilância das Doenças Transmissíveis. Manual de Normas e Procedimentos para Vacinação. Brasília: Ministério da Saúde, 2014a; 176p.

6. BRASIL. Ministério da Saúde. Informe técnico - Campanha nacional de vacinação contra a Poliomielite e de seguimento contra o sarampo: adaptado pelo Programa Estadual De Imunizações - RS. Brasília (DF): Ministério da Saúde; 2014b; 25p.

7. Brasil. Ministério da Saúde. Caderno do gestor do PSE / Ministério da Saúde, Ministério da Educação. - Brasília: Ministério da Saúde; 2015; 68 p.

8. BRASIL. Ministério da Saúde. Informe no 32 de 26 de novembro de 2018. Situação do Sarampo no Brasil. $2018 ; 9 p$.

9. BRASIL. Ministério da Saúde. Secretaria de Vigilância em Saúde. Departamento de Vigilância Epidemiológica. Coordenação Geral do Programa Nacional de Imunizações. Informe técnico campanha nacional de vacinação contra a poliomielite e contra o sarampo. Brasília, 2018b; 48p.

10. BRASIL. Ministério da Saúde. Informe no 17. Situação do Sarampo no Brasil-2018c, 17p.

11. FUNDAÇÃO DE VIGILÂNCIA EM SAÚDE. Fundação de Vigilância em Saúde do Amazonas. Boletim Epidemiológico de Surto de Sarampo no Amazonas no. 42. Sala de Resposta Rápida para o Surto de Sarampo no Amazonas, 2019; $4 p$.

12. HOMMA A, et al. Atualização em vacinas, imunizações e inovação tecnológica. Ciência \& Saúde Coletiva, 16 (2): 445-458, 2011.

13. MEDEIROS EA. Entendendo o ressurgimento e o controle do sarampo no Brasil. Acta Paul Enferm. $2020 ; 33$.

14. MOURA ADS, et al. Estratégias e resultados da vacinação no enfrentamento da epidemia de sarampo no estado do Ceará, 2013-2015. Epidemiol. Serv. Saude, Brasília, 27(1):e201634310, 2018.

15. SUCCI RCM. Recusa vacinal - que é preciso saber. JPediatr(RioJ).2018;94(6):574-581.

16. SUPERINTENDÊNCIA DE VIGILÂNCIA EM SAÚDE - SUVISA; Gerência de Vigilância e Controle de Doenças Transmissíveis - GEDT. Campanha de vacinação contra poliomielite e sarampo, 2018. Nota Informativa SUVISA no 26/2018. 11 de jul de 2018.

17. VIEGAS SMF, et al. A vacinação e o saber do adolescente: educação em saúde e ações para a imunoprevenção. Ciência \& Saúde Coletiva, 24(2):351-360, 2019. 